\title{
A novel gel immersion technique using a bipolar needle-knife in endoscopic submucosal dissection for superficial gastrointestinal neoplasms
}

\author{
Tomofumi Akasakaa, Yoji Takeuchi ${ }^{b}$, Hisashi Ishidaa ${ }^{a}$ Eiji Mita $^{a}$ \\ National Hospital Organization, Osaka National Hospital; Osaka International Cancer Institute, Osaka, Japan
}

We previously developed a water immersion ("underwater") technique for endoscopic submucosal dissection (ESD) to reduce adverse events $[1,2]$. We herein present a novel method of gel immersion ESD with the advantages of underwater ESD. We used a gel-type oral rehydration solution (OS-1 Jelly; Otsuka Pharmaceutical Factory, Tokushima, Japan) with balanced electrolytes and carbohydrates. Bipolar electrocoagulation is preferable to monopolar electrocoagulation in terms of dissipation of electrical energy and prevention of deep burns; therefore, we used a bipolar needle-knife with a water jet (Jet B-knife; Zeon Medical, Tokyo, Japan), which can emit water or gel from the tip of its sheath. We performed gel immersion ESD in 4 patients with superficial gastrointestinal neoplasms ( 1 in the esophagus, 2 in the colon, and 1 in the rectum). A 70 -year-old man was seen to have a laterally spreading tumor $30 \mathrm{~mm}$ in diameter in the descending colon (Fig. 1A). Gel immersion ESD provided clear visualization, and the gel viscosity provided a better and long-lasting submucosal cushion (Fig. 1B). When unexpected arterial bleeding occurs, it is often difficult to secure the visual field using air insufflation or water immersion (Fig. 1C). However, gel immersion secures a space for endoscopic visualization and treatment (Fig. 1D), as previously reported [3]. Since this method uses a bipolar device, current dissipation is limited, making it possible to immediately perform hemostatic procedures (Video S1). Finally, the lesion was resected in a single piece without adverse events (Fig. 2A,B). There were no adverse events in these cases.

Video S1 Gel immersion ESD using the Jet B-knife (Zeon Medical, Tokyo, Japan) for a laterally spreading tumor $30 \mathrm{~mm}$ in diameter in the descending colon

Departments of a Gastroenterology and Hepatology, National Hospital Organization, Osaka National Hospital (Tomofumi Akasaka, Hisashi Ishida, Eiji Mita); bastrointestinal Oncology, Osaka International Cancer Institute (Yoji Takeuchi), Japan

\section{Conflict of Interest: None}

Correspondence to: Tomofumi Akasaka, MD, PhD, Department of Gastroenterology and Hepatology, National Hospital Organization, Osaka National Hospital, 2-1-14 Hoenzaka, Chuo-ku, Osaka 540-0006, Japan, e-mail: akasak@gh.med.osaka-u.ac.jp

Received 27 November 2017; accepted 3 December 2017; published online 8 February 2018

DOI: https://doi.org/10.20524/aog.2018.0238

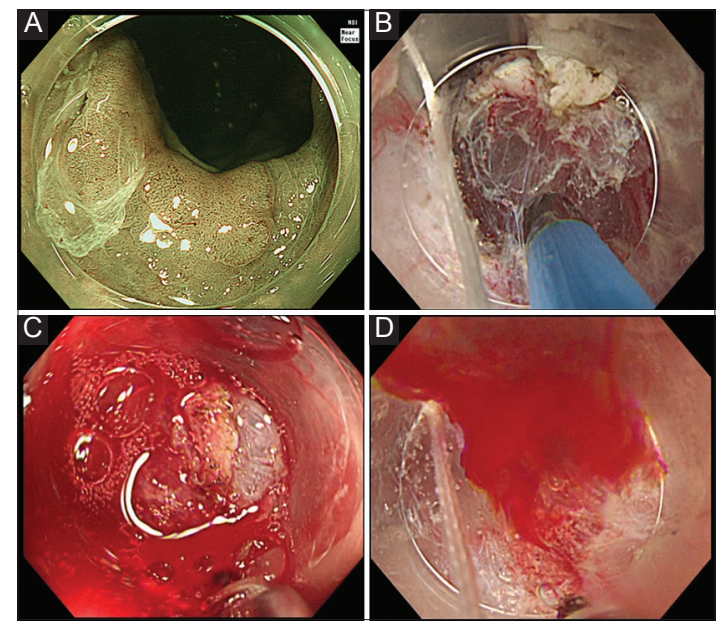

Figure 1 (A) Colonoscopy using narrow band imaging showed a laterally spreading tumor $30 \mathrm{~mm}$ in diameter in the descending colon. (B) The gel immersion method provided clear visualization and the gel viscosity provided a better and long-lasting submucosal cushion. (C) When unexpected arterial bleeding occurs, it is often difficult to secure the visual field using air insufflation or water immersion. (D) The gel immersion method can prevent rapid mixing with fresh blood, and secures a space for endoscopic visualization and hemostatic treatment

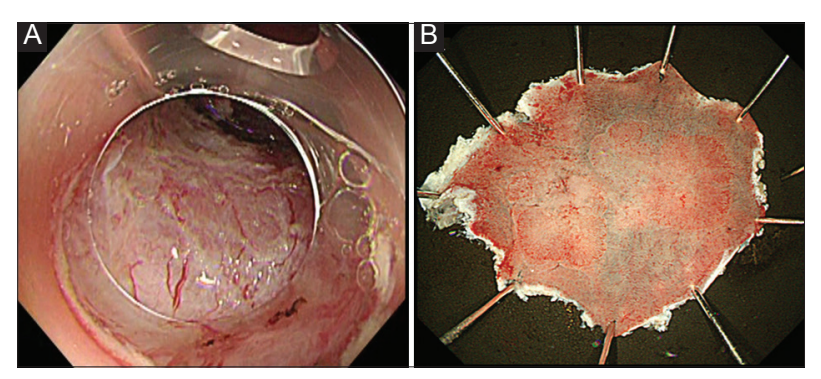

Figure $2(\mathrm{~A}, \mathrm{~B})$ The lesion was resected in a single piece without adverse events

\section{References}

1. Akasaka T, Takeuchi Y, Uedo N, Ishihara R, Iishi H. "Underwater" endoscopic submucosal dissection for superficial esophageal neoplasms. Gastrointest Endosc 2017;85:251-252.

2. Akasaka T, Tonai $\mathrm{Y}$, Hamada $\mathrm{K}$, et al. Dive to the underwater world: a water immersion technique for endoscopic submucosal dissection of gastric neoplasms. Am J Gastroenterol 2017;112:985.

3. Yano T, Nemoto D, Ono K, et al. Gel immersion endoscopy: a novel method to secure the visual field during endoscopy in bleeding patients (with videos). Gastrointest Endosc 2016;83:809-811. 